\title{
Education and childlessness: the relationship between educational field, educational level, employment and childlessness among Greek women born in 1955-1959
}

\author{
Christos Bagavos*
}

\begin{abstract}
In this article we expand the analysis of the relationship between educational attainment, educational field and fertility by presenting the case of Greece. The importance is emphasised of both educational field and occupation, as well as their role in the diversity of fertility observed among women. Our empirical investigation is based on census data (2001) pertaining to childbearing, educational and employment histories of an entire cohort of Greek women born in the country in 1955-1959. The analysis indicates that in some cases, the field of education serves better as an indicator of a woman's potential reproductive behaviour than the educational level attained. In general, the results show some similarities with those already obtained for other countries. In particular, women educated in teaching and health care have lower permanent childlessness at any educational level than any other major grouping. Our results confirm the findings of other studies that higher education does not systematically result in higher childlessness. Among the various factors related to an educational system, which may influence the relationship between education and childlessness, we emphasise the association of education with the labour market and mainly the distinction between employment opportunities in the public and in the private sector for highly educated women. We find that, in several cases, a woman's profession tends to modify the pattern of childlessness by educational field.
\end{abstract}

\footnotetext{
* Christos Bagavos, Panteion University, Department of Social Policy, Syngrou Avenue 136, Athens 176 71, Greece. Email: bagavos@panteion.gr
} 


\section{Introduction}

The persistence of very low fertility levels in the context of growing female participation in education draws a lot of interest in both academic literature and public debate. Low fertility has become a structural characteristic of the demographic regime in Greece. The combination of later timing with less intensity for successive cohorts has led to very low levels in the total fertility rate. According to recent estimates, the first-birth probability of women born in the late 1950s was 0.82 when reaching age 33 while, at the same age, the corresponding figure for those born ten years later was only 0.72 (Rendall et al. 2009). Moreover, in a time span of 10 years, the proportion of women with tertiary education increased from $20.3 \%$ (1955-59 cohorts) to $33 \%$ for those born between 1965 and 1969.

The negative relationship between educational level and fertility is one of the most common perceptions. Several explanations have been given about the association observed of high educational attainment with high permanent childlessness and low fertility levels. Economic approaches emphasise the ideas that highly educated women have to face the high opportunity costs of time spent on child care as well as the high direct costs of children, since they invest more than others in each child. Within the framework of traditional division of labour among partners, with one partner being in charge of household activities and the other participating in the labour market, these women tend to postpone parenthood and end up generally with a high proportion of childlessness and low fertility levels (Becker 1981; Shultz 1976; Cigno 1991). It is also argued that higher education for women is combined with weaker economic dependence on a (male) partner but also with the greater probability of finding partners who likewise have a higher level of education (Oppenheimer 1988; 1994). Both effects would lead to a higher proportion of childlessness among highly educated women, owing to the increase in single women among those with a high educational level (Hoem et al. 2006a) or to delayed parenthood, which is likely to be more pronounced for highly qualified men than highly qualified women (Kneale and Joshi 2008).

Cultural approaches to fertility focus on the role of education in diffusing new values and ideas (Lasthaeghe 1995; van de Kaa 1987). Rising education, which is interrelated with increased individualisation, value change and female emancipation, offers more lifestyle options and hence reduces the preference for children (Surkyn and Lesthaeghe 2004; van de Kaa 1996). This greater range of options offers more alternatives to the role of mother, and, by reducing the wish for children, as a consequence leads to fertility differentials among women of different educational levels (Hoem et al. 2006a).

It is further argued that low and late fertility reflects difficulties in balancing careers and motherhood (Kneale and Joshi 2008). Broadly, the degree of compatibility between work and family life, which most of the time is a matter of 
public policy, tends to mediate the effect of education on fertility (Kreynefeld and Konientza 2008). This is expected to be a particularly important issue for highly educated women who have strong career aspirations. In countries where work and family life are hard to reconcile, we would expect a higher rate of childlessness among highly educated women.

On the whole, most of the studies examining the association between educational attainment and fertility focus on the level of education and its impact on fertility, while at the same time, educational attainment is perceived as an individual attribute and is used "as a proxy for a person's human, economic, cultural and to some extent biological capital" (Hoem et al. 2006a). However, Hoem, Neyer and Andersson 2006a argue that childbearing behaviour is closely related to two other new dimensions, namely, the field of education and the institutional aspects of the educational system, and that these two dimensions should be considered when examining the association between final fertility outcomes and educational attainment (Hoem et al. 2006a). In their view, the relationship between childbearing behaviour and educational attainment is shaped by the structure and flexibility of the educational system, as well as by the gender pattern of the particular educational field. It is also influenced by the link between education and the labour market through job security, job content and job prospects, skill depreciation and gender dominance on the job for different educational groups. It is also argued that the choice of educational field reflects social norms and individual preferences, some of which may also relate to childbearing.

The main objective of our study is to investigate the empirical relationship between educational field, employment and fertility. The choice of Greece is driven by the fact that with Greek data, mere associations between these items can be identified, in particular between educational orientation and the labour market, an aspect which has not been addressed in empirical analyses in previous studies. By adding this dimension we are able to investigate the extent to which women's professions modify the pattern of fertility by educational field. However, the data do not allow investigation of the causal direction between the abovementioned items, since they do not contain any information on the timing of the completion of education and the onset of employment.

The article is organised as follows: Section 2 deals with the discussion on the relationship between educational field, occupation and fertility as well as with a review of previous studies on this topic. Section 3 follows with the methods and data used in the analysis. In Section 4 we present the characteristics of the educational system in Greece, and in particular those which are more relevant to our cohort. In Section 5 we outline the empirical relationships between educational level, educational field and childlessness. We find that the Greek pattern of childlessness by educational field has a lot in common with that found in other countries, with women educated in teaching and health care having lower levels of childlessness than most other professions on any educational level. 
Section 6 follows with an analysis of the role of employment in modifying the effect of educational orientation on permanent childlessness. Our results indicate that women's professions tend to modify the pattern of childlessness by educational field. Finally, in Section 7, the main findings are summarised and some implications for further research considered.

\section{Educational field, employment and fertility: theory and empirical research}

Educational orientation plays an important role in shaping childbearing behaviour. The choice of an educational line mirrors a woman's values and preferences, which may include her attitude regarding reproduction (Hoem et al. 2006b). At the same time, being enrolled in a particular educational line influences values and preferences and therefore impacts on future fertility decisions (Van Bavel, 2010). The study discipline can also affect social environment and social norms during the student's formative years regarding family and working life. This includes the degree of sex segregation in the chosen educational field, which may affect decisions on family formation (Hoem et al. 2006a; Van Bavel, 2010). Furthermore, the field of education reflects the structural factors of an educational system. In particular, the degree of flexibility of the system and the extent of sex segregation across educational fields may be relevant for a woman's potential reproductive behaviour. Since some femaledominated lines are often seen as conveying more stereotyped images than others of womanhood and motherhood, studying in such a line may provide an educational environment that encourages subsequent childbearing (Hoem et al. 2006a). Moreover, the choice of educational line tends to determine a person's future employment, which implies that the relationship between educational orientation and childbearing behaviour may be affected by the link between education and the labour market. More especially, the anticipation of future roles might imply educational choices as regards the field of study that will allow family and working life to be combined more easily (Lappegård and Rønsen 2005; Martín-García and Baizán 2006).

According to Hoem, Neyer and Andersson (2006a) a woman's field of education is likely to have an impact on her employment options, on the stability and protection of her employment, as well as on her income prospects. In our approach, we tend to underline the importance of both educational field and occupation on the diversity of fertility observed among women. In our view, the employment system has its own dynamic for shaping fertility behaviour but there is no doubt that it impacts on fertility through the educational field. Since different educational fields are matched with different jobs in terms of security, content, prospects and working conditions, combining educational orientations with a woman's profession must be relevant for studying the diversity of fertility 
among women. In this respect, economic implications, namely diverging wage profiles and opportunity costs related to particular educational qualifications, may be important and relevant in making fertility decisions (Van Bavel, 2010).

Two features of an educational system may be relevant to the role of employment in shaping fertility behaviour. First, the rigidity of an educational system does not allow individuals to combine work with education or to alternate employment and education. Being in education and being in the labour market are therefore usually two separate stages (episodes) in an individual's life. Secondly, when an educational system does not offer the option of interrupting one's education and re-entering it later, embarking on motherhood follows the completion of studies and usually occurs during employment. In that case, there are strong reasons to believe that employment, the next stage in an individual's life after education, could modify the pattern of fertility by educational field. Considering that these two features characterise the Greek educational system, there are strong reasons to believe that employment, more than educational field, is relevant in shaping childbearing behaviour.

In this article, the importance of types of education and employment for the diversity of childlessness for women awarded a university degree is analysed by emphasising three particular aspects: a) the distinction between occupation in a public or private sector, $b$ ) the different proportion of childlessness among women employed in the public sector (occupations with low vs. high income prospects) and c) the rate of permanent childlessness among women employed in particular professions in the private sector, namely the 'closed' professions.

We expected women employed in the public sector to display a lower rate of childlessness than women employed in the private sector. In fact, the public sector offers much greater job security and more opportunities for combining motherhood and employment through parental leave, compared with the private sector. Moreover, skill depreciation leads to the interruption of employment or reduced employment more often for people working in the private than in the public sector. Nevertheless, we must not underestimate the importance of 'closed' professions in the private sector, i.e. professions which are not open to competition and are often based on various criteria such as population size and geographical area. In Greece, this is an important aspect of the labour market. According to estimates, opening 13 of these professions to competitive market conditions could increase GDP by 1.5 units and real wages by $0.4 \%$ and decrease the cost of corresponding services by 10.5\% (KEPE 2005). Within this framework, it is likely that occupations offering job security and prospects of higher incomes will lead to higher fertility outcomes, irrespective of the employment sector (private or public).

Only a limited amount of empirical research has been carried out on the importance of educational fields for fertility outcomes in Europe. The large majority of these studies concentrate on one country and to the best of our knowledge, there is no previous study empirically investigating the association 
between educational field, occupation and fertility. Kalmijn (1996), cited by Van Bavel (2010), concludes that in Germany, women educated in social and cultural sciences have higher first-birth rates than those trained in business or technology. A Norwegian study using register data found that the field of education plays a more important role in women's fertility than the level (Lappegård 2002). The author concludes that the proportion of childlessness among women with a degree in female-dominated fields is relatively low and, after becoming a mother, these women are more likely to have a high level of completed fertility. In a second study on Norway, using longitudinal data, Lappegård and Rønsen analysed the role of educational field in women's first-birth rates. They found low motherhood rates for women educated in the humanities, social sciences, engineering, and administration and economics, while high first-birth rates were observed for those trained as teachers and health care professionals. They argue that low first-birth rates are related to the unfavourable position for women with a degree in the humanities or social sciences in the labour market, while for those with a qualification in engineering or administration and economics, low motherhood rates are due to that fact that those women are less family and more work oriented. The association between educational field and fertility outcomes has also been studied for the case of Spain (Martín-García 2009; Martín-García and Baizán 2006). These authors used data from the Spanish Family and Fertility Survey and applied event history models that take into account the presence of unobserved heterogeneity. They found that the type of education is as important as the level for women's reproductive behaviour. In particular, better-educated women trained in the care of individuals and in relational skills show lower levels of childlessness compared with those in the category 'others' at the same educational level, and even compared with women educated to intermediate level. The authors speculate that their results are due to the fact that these educational lines are related to jobs in education, personal services, health etc., which may be seen as extensions of the traditional roles of women. It is argued that women with favourable values and attitudes towards family and fertility tend to opt for these fields of education.

In two very stimulating studies, Hoem, Neyer and Anderson (2006a, 2006b), using register data, found that in Sweden both childlessness and ultimate fertility are more closely related to the field of education than to the educational level. In particular, women educated in teaching and health care have much lower permanent childlessness than those in any other major group. The proportions of women educated for jobs in the arts and humanities or for religious occupations and remaining permanently childless are high. Basically the same results were obtained for Austria in a study using census data and comparing the Austrian with the Swedish case (Neyer and Hoem 2008).

In a multilevel logistic regression analysis, Van Bavel (2010) studies the mechanisms relating the field of education to the postponement of motherhood. $\mathrm{He}$ identifies four features of the study discipline as the key to reproductive 
decision making: the expected starting wage, the steepness of the earning profile, attitudes towards gendered family roles and gender composition. By using data from the second round of the European Social Survey on women graduates aged 20 to 40 years old and covering 21 European countries, he concludes that the study discipline appears to be clearly related to entry into motherhood in Europe. In particular,

"the postponement of motherhood is relatively limited among graduates from study disciplines where stereotypical family attitudes prevail and where a large number of the graduates are female. Both the level of the starting wage and the steepness of the earning profile are found to be associated with strong postponement."

Nevertheless, none of the research mentioned above has studied the empirical relationship between educational field, occupation and fertility. The current article will use census data in order to shed light on this and in particular, will emphasise the importance of employment in modifying the pattern of childlessness by educational field.

\section{Data and methods}

Individual-level data for Greek women born in Greece between 1955 and 1959 are used in this study. We have chosen this single five-year birth cohort in part because we wanted to focus on women who had largely reached the end of their reproductive life at the time of the census, but also for reasons of data quality. Younger cohorts have not become old enough and for older cohorts, the rate of information on educational field missing is higher than for the 1955-1959 birth cohort.

Our cohort comprises about 350,000 women. The data on citizenship, place of birth, fertility, education and occupation have been extracted from the 2001 population census and the corresponding data set was supplied by the National Statistical Service of Greece. Fertility levels were estimated on the basis of the numbers of children ever born alive to the women reported at the time of the census. This question was addressed to all women aged 15 and over. In the present article only the results referring to childlessness are presented.

The women were also asked about the highest educational level they had attained. There were 13 different answers to this question. One of those 13 answers ("Attends primary school") is irrelevant to our analysis and is therefore omitted. This is also the case for another 2 answers namely, "Left primary school without any certificate, but knows how to read and write" and "Does not know how to read and write". The 10 remaining educational levels were classified in 5 categories: primary, intermediate, high school, low-tertiary and high-tertiary education (see below).

Women with a tertiary (low or high) level of education, a total number of around 60,000 individuals, were asked about their academic qualifications by 
means of the following sub-questions: a) Educational institution, b) School (if any), c) Department (if any), d) City and e) Foreign country. On the basis of the information on schools and departments we obtained information on the women's educational qualifications. For instance, any university graduate from one of the two dentistry schools was classified as a dentist with a 'high-tertiary' level of education. In a similar way, women with a 'low-tertiary' diploma from one of the eight departments of nursing were classified as nurses with the corresponding level of education. On the basis of the international standard classification of education (ISCED classification of 1997), this procedure was applied for the total number of 454 educational departments (212 in high-tertiary and 242 in lowtertiary education) in order to obtain classification by both educational field and level. For about 3,300 (5.5\%) of the women in our cohort the educational field is unknown and for about $700(1.2 \%)$ the information was omitted since it refers to women in small odd groups.

Using the international standard classification of education as well as similar studies regarding Austria and Sweden (Neyer and Hoem 2008; Hoem et al. 2006a), educational fields were re-coded into some 50 groups and further summarised into seven main educational fields. Some fields and levels of education need further clarification. First, the category of women with a qualification in high school teaching is not as clear cut as we would have liked. Since, in Greece, there is no additional qualification for being a high school teacher (in the public sector), this educational field was derived by combining information on educational fields and professions. The category comprises women with a qualification in the humanities, theology, natural sciences, social sciences and economics and business. Secondly, the educational fields for preschool and primary (i.e. junior) school teachers were classified as low-tertiary level, since the vast majority of the women in our cohort were educated in Teacher Training Academies (a 2-year training course) and not in universities. Teacher training departments for the two educational fields mentioned were set up in fact by law in the universities in 1982. The same applies for women educated in physical education and home economics.

In the 2001 census, women who reported that they were 'working' or were 'job seekers' were asked about their most recent profession. The various professions ${ }^{1}$ were classified, by the National Statistical Service, using 210 codes. In our analysis, there were women with the educational level of a Master's degree or a Ph.D. in 98 different occupations, with a university degree in 165 and with a low-tertiary educational level in 154. The response rates relative to (known) professions were $90.9 \%, 88.2 \%$ and $77.8 \%$ respectively for the three educational levels mentioned.

Table 1 presents further information on the marital and employment status of our entire cohort of women related to their different educational levels. Around 7

1 We use the terms "occupation", "employment" and "profession" as synonymous. 
per cent of all the women in our cohort have remained single throughout their lives.With the sole exception of women with intermediate education, the proportion of those who never married increases as we move towards the higher educational levels. The opposite trend is observed for non-economically active women, since the higher the educational level, the lower the proportion of women working solely as homemakers. While for the entire cohort the proportion of women working solely in the home is $39.1 \%$, the figures are only $15.2 \%$ and $6.8 \%$ respectively for those with high and low-tertiary levels of education. On the whole, there seems to be a clear division by educational level for both marriage and participation in the labour market.

Table 1:

Employment and marital status by educational level*; Greek women born in 19551959

\begin{tabular}{lcc}
\hline & $\begin{array}{c}\text { Proportion of women } \\
\text { who never worked } \\
\text { outside the home }\end{array}$ & $\begin{array}{c}\text { Proportion of women } \\
\text { who never married }\end{array}$ \\
\hline 6-year comprehensive junior schooling & $50.4 \%$ & $4.0 \%$ \\
Primary education & $50.6 \%$ & $5.1 \%$ \\
Intermediate education & $32.9 \%$ & $7.3 \%$ \\
High school education & $39.5 \%$ & $6.8 \%$ \\
Low-tertiary education & $15.2 \%$ & $9.3 \%$ \\
High-tertiary education & $6.8 \%$ & $12.3 \%$ \\
All & $39.1 \%$ & $6.8 \%$ \\
\hline
\end{tabular}

Note: *For a detailed description of educational levels see Section 4 and Figure 1

Our method of analysis is straightforward. In the first stage, fertility outcomes, namely the percentage of permanently childless women, were computed for each educational level in terms of both level and field of education. Based on previous studies (Hoem et al. 2006a and 2006b), the results are mainly presented in diagrams. In the second stage, some results referring to the rate of childlessness among women with specific educational levels and fields were contrasted with the women's professions. Some interesting issues thus arise relative to fertility differentials by educational level, field of education and occupation.

Our data do not allow any investigation into the causal direction between occupation, educational field and fertility. Since a sophisticated modelling strategy that takes into account the timing of fertility and onset of employment is not possible, our main effort is to present descriptive tables that contain relevant information regarding these choices. The analyses the article therefore presents focus merely on associations. We consider that the choice of educational field has temporal priority over entry into motherhood and that employment is the next 
stage in an individual's life after education. With these considerations in mind, the article aims to investigate the extent to which the occupation modifies the pattern of childlessness by field of education.

\section{The Greek educational system}

In this section we briefly present the main features of the Greek educational system that are the most relevant for our cohort. In Greece, the educational system is structured on three levels: primary, secondary and tertiary education (European Commission 2003).

Primary education consists of 6-year comprehensive junior schooling, mandatory for all children between 6 and 12 years of age. Pupils follow largely a standard curriculum at this level. In our cohort, primary education was the highest level attained by $37.4 \%$ of the women ${ }^{2}$ (Figure 1 ).

Secondary education has two levels, namely lower and upper secondary education. The compulsory lower education (Gimnassio) offers general education to children between 12 and 15 years of age and lasts for 3 years. $8.2 \%$ of the women in our cohort completed at most lower secondary education. Compulsory education consists of primary and lower secondary education, i.e. 9-year comprehensive schooling. In our analysis, compulsory education was all classified as 'primary' education.

Upper secondary education is mostly directed towards pupils aged from 15 to 18 years old. It covers both vocational (Technical Vocational Education Schools, TEE) and general academic education (the Unified Lyceum or Eniaio Lykeio). Eniaio Lykeio was established in 1997. All other forms of lykeia that used to exist before, which are the most relevant to our cohort, i.e. general, classic, comprehensive, technical vocational, musical and ecclesiastical were transformed into Eniaio Lykeio. Technical Vocational Education Schools (TEE) were established in 1998 and therefore are not relevant to our cohort. Upper secondary education, in its various forms, was the highest level attained for around 1 in 3 women $(30.3 \%)$ in our cohort. In this article, upper secondary education was classified as the 'high school' educational level.

It is worth noting that some $2.5 \%$ of the women in our cohort did not even complete primary education. 
Figure 1:

Greek educational system with emphasis on 1955-1959 birth cohorts

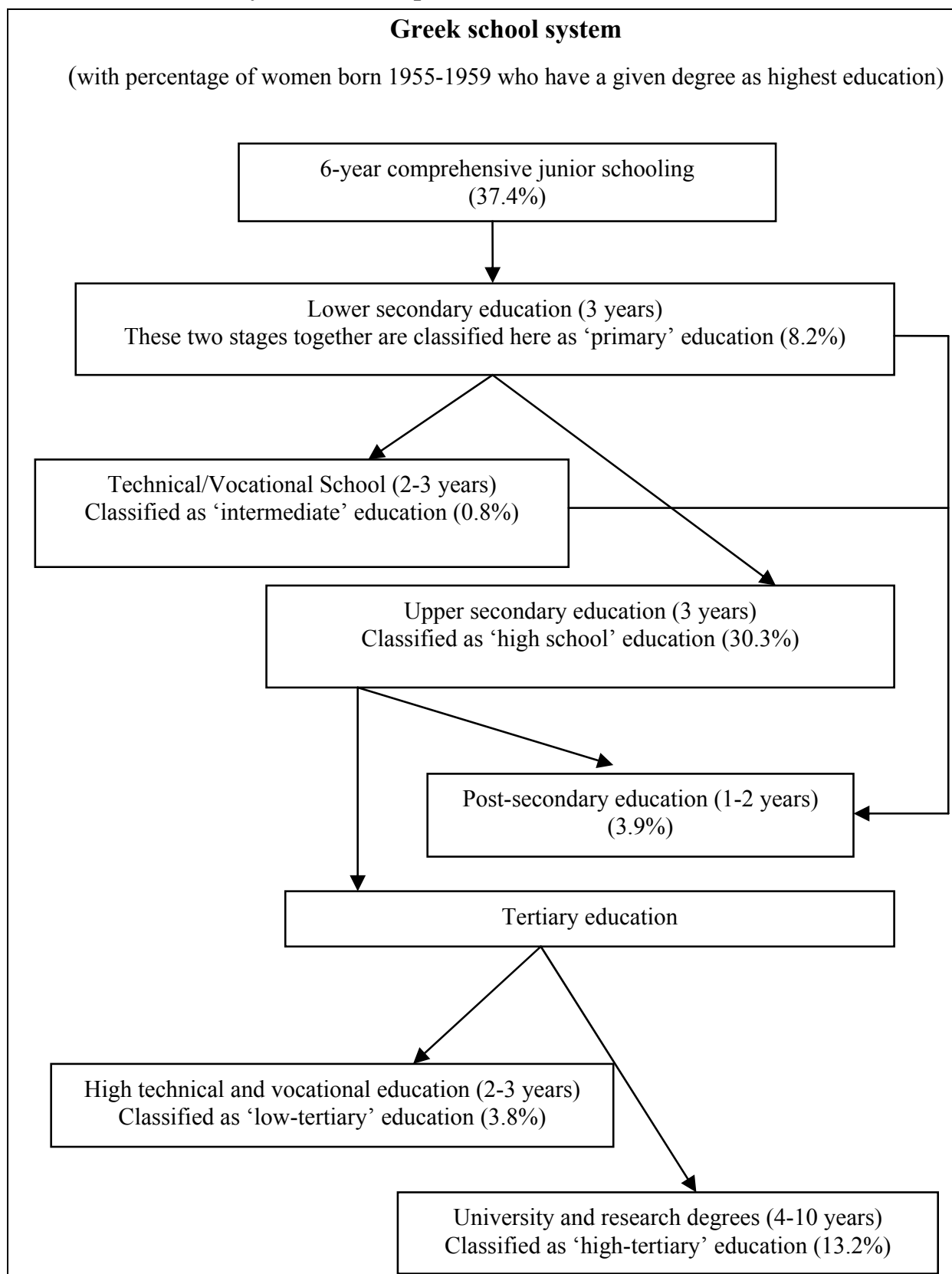


Women in our cohort, who completed lower secondary education, had the option of choosing a Technical Vocational School (TEE). In our analysis, this form of vocational education was classified as the 'intermediate' educational level (between lower and upper educational levels). Some $0.8 \%$ of the women born between 1955 and 1959 ended their school career with 'intermediate' vocational education.

Women in our cohort who had completed upper secondary education could achieve a tertiary educational level ${ }^{3}$ by attending either of two institutions: a university or a Centre for Higher Technical and Vocational Education (KATEE, or KATE in its previous form). Centres for Higher Technical and Vocational Education, which were transformed in 1983 into Technological Educational Institutions (TEI), provided 2 to 3 years' training, focusing on advanced technical and vocational education. These 'low-tertiary' institutions offered specialisations in graphic arts and artistic studies, administration and economics, health and welfare occupations, technological applications, food and nutritional technology, agronomy technology and music technology. Moreover there are certain schools that are considered 'Higher' providing non-university tertiary education. These schools provide certain categories of tertiary or special education with studies at the most of three years, and do not fall under either of the two main types of tertiary education. The most relevant schools for our analysis are the higher schools of dance and drama and the higher schools of tourism. These two schools together with institutions providing higher technical and vocational education were classified in the 'low-tertiary' educational level. Some $3.8 \%$ of the women in our cohort ended their education at this level.

University education, undertaken in the universities, technical universities and the Athens school of fine arts, offers a 'high-tertiary' degree to undergraduates after a minimum of 4 years of study ( 5 years for technical universities and 6 years for medical schools) in the fields of the humanities, law, social sciences, health sciences, technology, economics and administration and natural sciences. At universities there are postgraduate study programmes that lead to the granting of a postgraduate specialisation research degree (a Master's degree) and/or a $\mathrm{PhD}$. These programmes last from 1 to 2 years for a Master's and usually 4 years for a $\mathrm{PhD}$. In our analysis, university graduates and holders of a Master's or $\mathrm{PhD}$ degree were classified as having 'high-tertiary' education. Some $13.2 \%$ of the women of our cohort ended their education at this level $(12.4 \%$ obtained a university degree and $0.8 \%$ a Master's or a $\mathrm{PhD}$ degree).

In order to give a complete picture of the various educational levels in Greece, we have to mention the existence of a 'post-secondary' educational level provided by public and private Vocational Training Institutes (IEK), as well as by private colleges. Nevertheless, since access to IEKs is open both to those who have completed lower or upper secondary education, these institutions do not fall

3 The number of students admitted to tertiary education was and still is determined by the Ministry of National Education. 
within any specific category and hence, this level cannot be considered as a real post-secondary educational level. In our cohort, some $3.9 \%$ of the women left the school system through this route.

The Greek educational system puts great emphasis on general academic rather than technical and vocational education. There is a distinction between these types of education resulting in pupils and students clearly preferring to attend classes of general rather than technical and vocational education. In fact, technical and vocational education constitutes a 'second-rate choice' in the preferences of individuals.

The Greek educational system is rather closed and rigid. The application of a 'numerus clausus', determined by the Ministry of National Education allows access to tertiary education only of a restricted number of individuals who have completed the upper secondary education level. It does not offer the possibility of interrupting a course and re-entering the educational system later, while opportunities to retrain or refresh knowledge are rare and change in educational choices is not facilitated. In fact, the option of changing one's mind regarding the educational orientation chosen is virtually non-existent. However, the system does allow a student to study longer than the minimum number of years necessary for graduating. It has been estimated that of several European countries, Greece has the highest average duration ( 7.1 years) of tertiary education (European Commission 2009).

The aim to promote educational attainment has led to the growing participation of women in education (Bagavos 2004). The educational gap between men and women has disappeared as the number of years people devote to their education has increased much more for women than for men (AliprantiMaratou et al. 2002). The high participation rate in particular in tertiary education (16.4\% for those aged 18-39 years in 2003) goes with the high proportion of women studying at this level (the male/female ratio was 0.88, European Commission 2009). Nevertheless, gender segregation by educational field still persists. Women continue to be the large majority of students in teaching, the humanities, arts and health and welfare (around 3 out of 4 students are female) while they are less well represented in engineering, manufacturing and construction as well as in science, mathematics and computing. 


\section{Main results of the empirical relationship between educational level, field of education and permanent childlessness}

\subsection{Educational level and permanent childlessness}

Figure 2 displays the results of the breakdown of childlessness by educational level. With the sole exception of those with intermediate education, the proportion of women who have remained permanently childless increases as we move up the educational levels. The proportion of childlessness is particularly pronounced for women with a high-tertiary level of education $(19.6 \%)$ and is very limited for those with just comprehensive junior education $(8.2 \%)$. Overall, there seems to be a clear difference in fertility behaviour between women who have been educated to tertiary level and those with comprehensive junior, primary, intermediate or high school education.

\subsection{Main features of the empirical association between educational field and permanent childlessness}

Cross-tabulating the main educational fields by the number of children showed that there is a significant relationship between the two variables $(\mathrm{N}=59597$, $p=0.000){ }^{4}$ Figure 3 displays our main results for childlessness. We outline only the main educational fields relevant to our study of childlessness. The markers of various forms and colours refer to the various educational fields. In order to simplify the graphical representation of the findings, some subcategories of educational orientation are omitted despite the fact that we sometimes refer to them in the text.

Our results indicate that a higher level of education is associated with lower fertility, but this mainly applies within the same educational field. For instance, women educated in agriculture (11.3\%) and veterinary science (13.6) at lowtertiary level are less likely to remain childless than those in the same educational line who have a university degree $(17.3 \%$ and $23.4 \%$ respectively). The same pattern is also observed for women trained in business and administration, namely accounting and taxation ( $13.1 \%$ vs. $14.2 \%)$, business administration $(14.4 \%$ vs. $15.1 \%)$, management and administration (13.5\% vs. $18.3 \%)$, and sales (16.3\% vs. $26.3 \%)$, as well as in technical sciences, namely engineering (15.3\% vs. $22.8 \%)$, architecture and building (15.7\% vs. $23.3 \%)$.

\footnotetext{
Comparing the means within the main categories of educational field resulted in standard deviations ranging from 0.0 to 2.3 depending on the number of cases in each category (i.e. in the three instances of the largest standard deviations 2.12, 2.12 and 2.30 the number of cases was 2,2 and 3 , respectively).
} 
Figure 2:

Childlessness by level of education*; Greek women born in 1955-1959

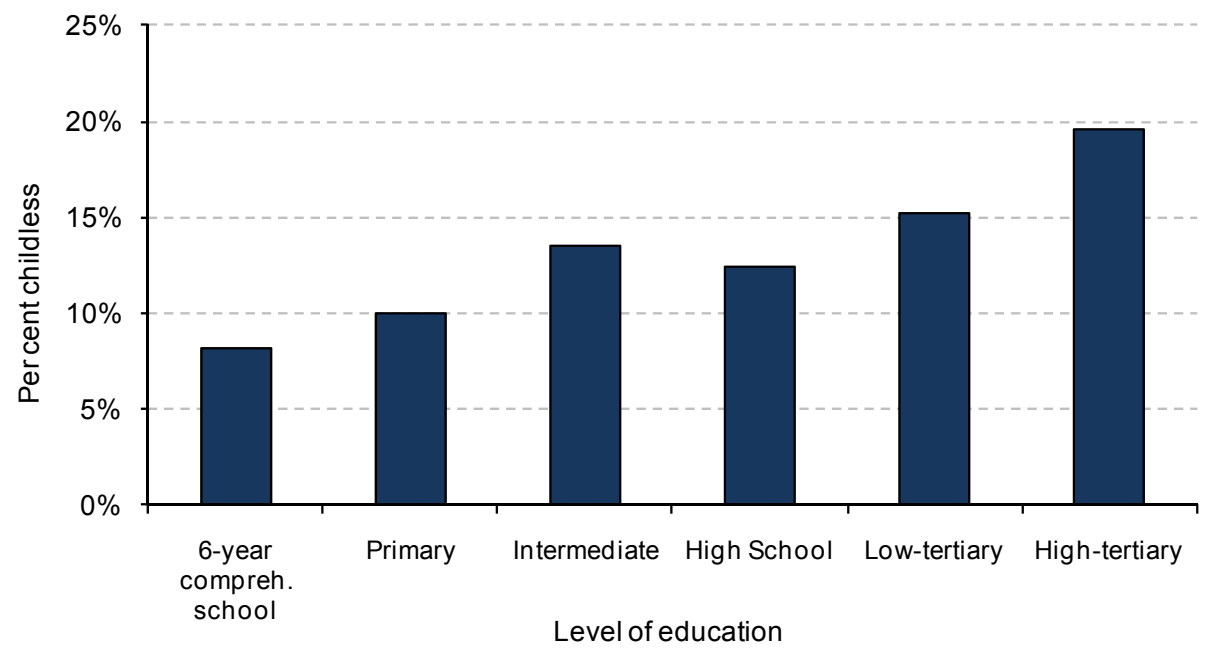

Note: * For a detailed description of educational levels see Section 4 and Figure 1

Diversity of fertility is related to the educational qualification obtained and to the educational level attained to a rather similar extent. For instance, women with an educational specification as pre-school teachers have a similar level of childlessness $(9.3 \%)$ to women who did not complete more than primary education (10\%). In two other subcategories of teachers, namely home economics teachers $(11.9 \%)$ and primary school (junior school) teachers $(11.9 \%)$, there is a lower proportion of women who remain childless than among women of intermediate (13.5\%) or high school (12.4\%) educational level. Women who have completed a university degree in dentistry are likely to remain childless to a similar extent $(14.8 \%)$ to those with a low-tertiary level of education in early childhood care $(14.9 \%)$, as medical assistants $(15.3 \%)$, in engineering $(15.3 \%)$ or in architecture and building (15.7\%). Moreover, they have a lower level of childlessness than those with low-tertiary education in educational lines such as sales $(16.3 \%)$, optics $(17.6 \%)$, social work $(18.7 \%)$, tourism $(20.0 \%)$, computing $(21.0 \%)$, librarianship $(24.7 \%)$ or the arts $(26.0 \%)$. This applies to a certain number of other educational lines at university level, namely business administration (15.1\%), agriculture (17.3\%) and pharmacy (17.4\%). 
Figure 3:

Percentage of permanent childlessness by educational field and level; Greek women born in 1955-1959

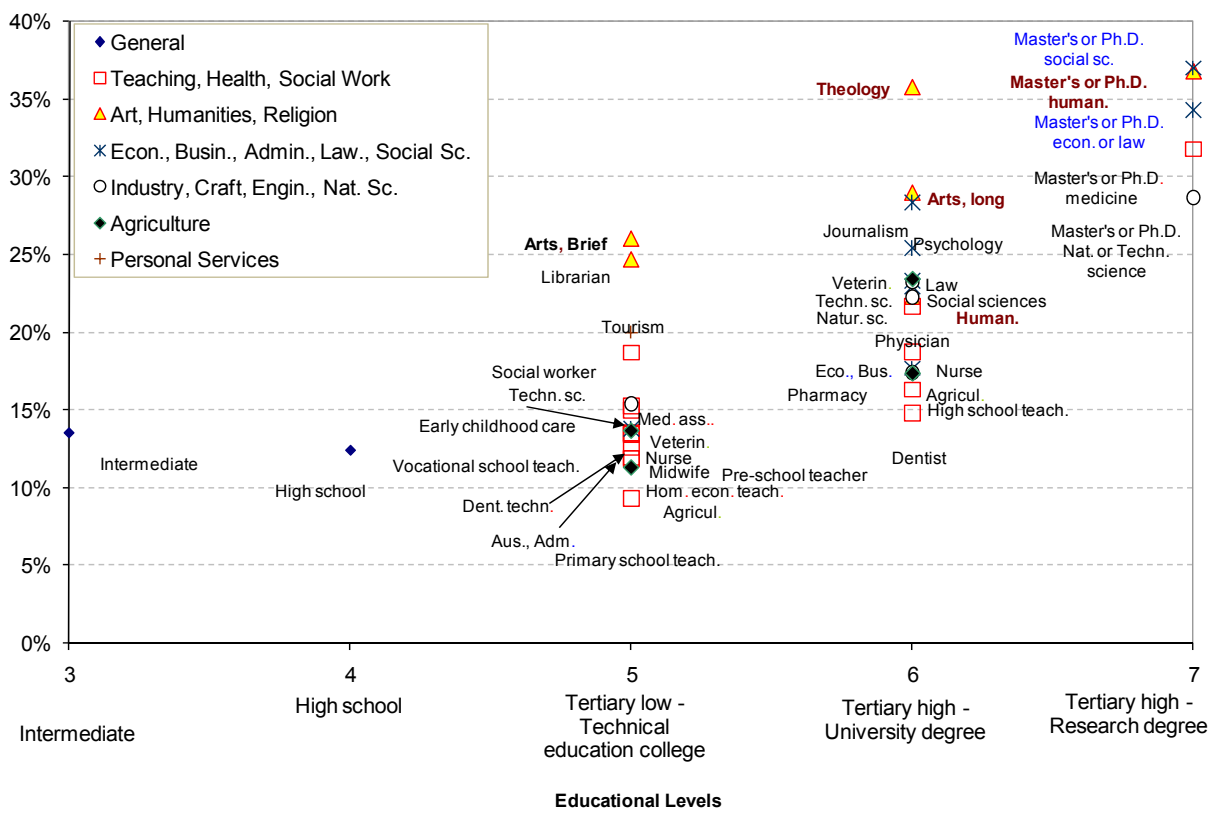

The proportion of women educated in teaching (14.0\%) or health care $(13.8 \%)$ remaining childless is typically lower than in any other major grouping of educational fields. In contrast, women educated as theologians, artists, librarians or humanists $(23.5 \%)$ have much higher childlessness than any other group. More than one in three women with an education in theology remains childless $(35.8 \%)$ whereas for humanists the corresponding figure is more than 1 in $5(22.2 \%)$. It is worth noting that women with the same background who work as high school teachers have significantly lower childlessness (high school teachers in theology: $23.1 \%$; high school teachers in humanities: $16.8 \%$ ).

The proportion of childlessness for women with an education in social sciences, economy, administration and law (19.1\%) does not significantly differ on average from that of women with an education in natural sciences $(20.0 \%)$ or in technical sciences (industry, crafts and engineering, 20.3\%). However, educational level is important for the diversity in the rate of childlessness within subcategories of the corresponding educational field. Indeed, women with a university degree in certain subcategories (namely the social sciences, the natural sciences, engineering, architecture or law) have a high level of childlessness ( $22 \%$ or higher).

The Greek pattern of childlessness by educational level shows that fertility outcomes must be considered in relation to both educational field and level of 
education. Like most other authors, we have found that in several cases educational line is a much better indicator of permanent childlessness than educational level.

\subsection{Conceptual outliers}

Our results indicate that, in terms of childlessness, we have to pay attention to three educational groups.

\subsubsection{Conceptual outliers 1: Groups with a very high proportion of permanent childlessness}

Women educated in the arts and theology show very high levels of childlessness. Some features appear for women in those educational fields, which are likely to highlight a selection process. The percentages of women with an educational qualification in theology or the arts who have never married are very high (more than 16\%). In our cohort, around two thirds of women with an education in theology work as high school teachers and they have higher rates of childlessness $(23.1 \%)$ than the entire group of high school teachers taken as a whole $(16.3 \%)$. About one third go into other occupations or do not participate in the labour market and the proportion of childlessness among them is very high $(35.8 \%)$. Even those who have never worked very often remain permanently childless $(31.3 \%)$. Women of the same educational level and trained in the arts have very high rates of childlessness irrespective of participating or not in the labour market $(29.0 \%$ and $30.3 \%$ respectively). The figures are very high even for those who are teachers in high schools $(28.5 \%)$ or who are working in other occupations $(29.3 \%)$. In fact, the proportions for childlessness among women in both educational fields are high, despite the fact that, very often, they have regular and secure employment as teachers.

\subsubsection{Conceptual outliers 2: Women that never marry}

Despite the fact that in recent years in Greece the proportion of births outside of marriage has been increasing, for the 1955-59 cohort, being married constituted the 'necessary step' prior to pregnancy. We have combined the percentage remaining childless in our educational groups with the percentage that never married (Figure 4).

We can observe a clear positive relationship between these two variables, since proportions childless increase with the increasing percentage of women never married. Nevertheless, in several cases, differences in permanent childlessness tend to be more pronounced than those observed among women who have never married. 
Figure 4:

Percentage permanently childless vs. the percentage never married; Greek women born in 1955-1959

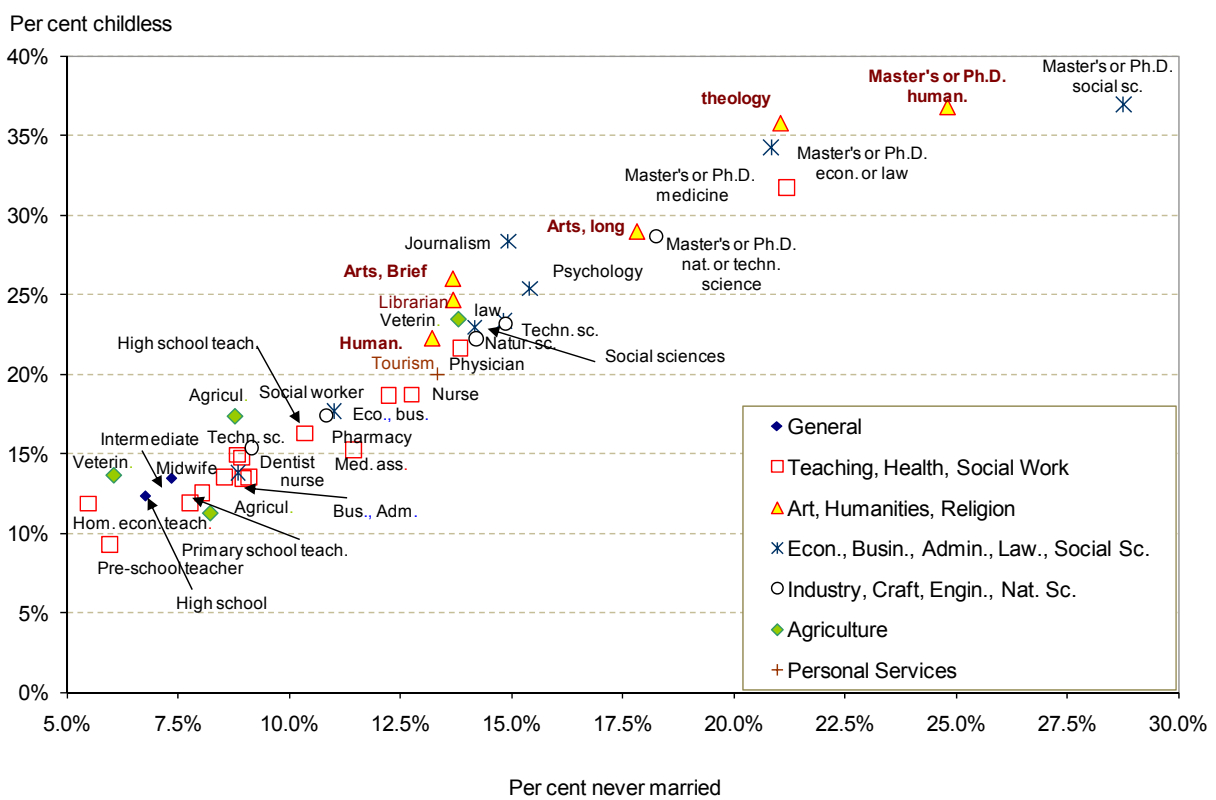

For instance, despite the fact that the proportion of women with low-tertiary education in agriculture who never married $(8.2 \%)$ is similar to that of those in the same educational field but at university level $(8.8 \%)$, they tend to remain permanently childless less often $(11.3 \%$ vs. $17.3 \%)$. The proportion of women educated as physicians who never married $(13.8 \%)$ is the same as that of those having a brief education in the arts $(13.7 \%)$ or those qualified as librarians $(13.7 \%)$ but their rates of childlessness are significantly different $(21.6 \%, 26.0 \%$ and $24.7 \%$ respectively). This is likely to indicate that, in some cases, the 'direct' impact of education on fertility outcomes is more important than the corresponding impact observed through marriage patterns.

\subsubsection{Conceptual outliers 3: Women with research degrees}

The percentages of women with research degrees remaining childless tends to be high and to that extent these women appear systematically different from others. The proportion of them remaining childless, irrespective of educational field, is nearly three times higher $(31.7 \%)$ than the average rate of childlessness in our entire cohort (12.3\%). Both economic and culture-based theories lead to exceptionally high proportions of childlessness being expected among these most highly educated women. 


\section{Employment, educational field and permanent childlessness}

Investigation into the importance of occupation in shaping fertility outcomes must take into consideration the simple association between the participation of women in the labour force and childbearing behaviour. Table 2 presents information on childlessness and employment status for the women in our cohort with a university degree. This information is provided for selected educational fields which will be further analysed in terms of occupation in this section.

Table 2:

Childlessness, educational field and employment status; Greek women with a university degree born in 1955-1959

\begin{tabular}{lc|ccc}
\hline & & \multicolumn{3}{|c}{ Percentage childless } \\
\cline { 3 - 5 } & $\begin{array}{c}\text { Proportion of } \\
\text { women who } \\
\text { never worked } \\
\text { outside the } \\
\text { home }\end{array}$ & $\begin{array}{c}\text { Women not } \\
\text { employed } \\
\text { outside the } \\
\text { home }\end{array}$ & $\begin{array}{c}\text { Women } \\
\text { participating in women } \\
\text { the labour } \\
\text { market }\end{array}$ \\
& & & & \\
\hline Economics and business & $9.5 \%$ & $9.8 \%$ & $18.5 \%$ & $17.6 \%$ \\
Natural sciences & $5.9 \%$ & $14.8 \%$ & $17.6 \%$ & $17.7 \%$ \\
Humanities & $6.5 \%$ & $14.8 \%$ & $19.2 \%$ & $19.1 \%$ \\
Social sciences & $11.4 \%$ & $13.5 \%$ & $23.4 \%$ & $22.7 \%$ \\
Law & $6.4 \%$ & $15.4 \%$ & $23.8 \%$ & $23.3 \%$ \\
Theology & $4.6 \%$ & $31.3 \%$ & $24.7 \%$ & $26.6 \%$ \\
All (with a university degree) & $6.9 \%$ & $13.1 \%$ & $19.0 \%$ & $18.9 \%$ \\
All (entire cohort) & $39.1 \%$ & $8.2 \%$ & $13.6 \%$ & $12.3 \%$ \\
\hline
\end{tabular}

Two results are remarkable: first, in almost every educational field, the proportion of women who have never worked outside the home and remain permanently childless is lower than for those who have ever participated in the labour market. This holds true for all women with a university degree and for our entire cohort with the exception of those trained in theology. In this last educational line, women participating in the labour market remain childless more often than those working solely as homemakers. This result is probably related to the small number of women not employed outside the home (16) with no children (5), but it is also likely that it indicates a selection process for women in these educational fields. Secondly, differences across educational fields as regards the proportion of women that never worked in the labour market, are not necessarily reflected in the corresponding fertility differentials. Indeed, despite the fact that some educational fields generate more women remaining in the home (for instance, social sciences $-11.4 \%$ ) than others (law $-6.4 \%$ ), their rates of childlessness do not essentially differ ( $22.7 \%$ and $23.3 \%$ respectively). It is also 
worth noting that women educated in economics and business have the lowest percentage of childlessness $(17.6 \%)$ while the proportion that never worked in the labour market (9.5\%) is higher than in most other educational lines. On the whole, it is likely that being in the labour market, or not, is less relevant for patterns of fertility by educational field than being employed, or not, in specific professions.

In order to identify the role of employment in fertility patterns by educational field better, we first underline the importance of occupation in the public and the private sector for the diversity of fertility among women. In particular, we study differences in the proportions childless of women educated in the humanities and natural sciences who are employed as secondary education teachers ${ }^{5}$ in the public or private sector. In Greece there is a kind of a parallel educational system providing tuition in private educational institutions (called frontistirio) as a complement to secondary public education, in order for pupils to improve their knowledge in particular subjects. In the analysis we compare permanent childlessness for teachers employed in public and private (frontistirio) education. The distinction between public and private sector employment is also studied by analysing the diversity of childlessness among women trained in economics and business who worked as freelance economists or administrators in the public sector or as customs, tax and related government-associated professionals. The results for the last two subcategories are also used for analysing the second aspect, i.e. the effect of low vs. high income occupations on ultimate childlessness among women employed in the public sector. The third aspect is analysed through the difference in the proportions childless of women with a university degree in law who are employed in 'closed' professions of the private sector, such as as public notaries.

Our results referring to the importance of both educational field and occupation for the observed diversity in fertility are presented in Table 3 . They show that a woman's profession tends to modify the pattern of ultimate childlessness by educational field within the various types of education. We observe that the percentage of childless women employed as secondary education teachers in the public sector is lower than for those in private education $(16.3 \%$ vs. $21.4 \%$ ). Within the same occupation, this diversity holds true for different educational fields, namely women educated in the humanities (16.8\% vs. $21.9 \%)$ and in natural sciences (13.7\% vs. $17.2 \%)$.

The role of employment sector (private vs. public) is also reflected in the results regarding women with an educational orientation in economics and business. In fact, women employed as freelance economists remain childless more often $(26.3 \%)$ than those in public service administrative professions $(17.5 \%)$ or in customs, tax and related government-associated professions (11.4\%). It is worth noting that the permanent childlessness of women in the last occupational category is among the lowest levels irrespective of educational level or field of

5 We use the terms 'secondary education teachers in the public sector' and 'high school teachers' as synonymous. 
education. This result is likely related to higher income opportunities compared with other women of the same educational field and employment sector (public), since customs, tax and related government-associated professions are among the better paid jobs in the public sector. An interesting result is observed for women educated in law who worked as public notaries, since they have the lowest percentage of childlessness $(16.3 \%)$ among women in the legal professions ( $28.9 \%$ for lawyers and $24.7 \%$ for public prosecutors and judges). This diversity must be seen in relation to the fact that, in Greece, the profession of public notary is typically closed and not open to competitive market conditions. It is a profession 'transmitted' from retired public notaries to younger public notaries and offers employment security and great prospects for high income.

An equally important feature of our results is that a woman's profession tends to modify the pattern of childlessness by educational field across the various types of education. For instance, women educated in law have higher childlessness $(23.3 \%)$ than those with an educational qualification in the humanities $(19.1 \%)$ or economics and business (17.6\%). However, public notaries have a similar percentage of childlessness $(16.3 \%)$ to high school teachers trained in the humanities $(16.8 \%)$ and they remain less often childless than humanists who do not work as secondary education teachers $(22.4 \%)$, or freelance economists $(26.3 \%)$. Differences in permanent childlessness by educational field are less pronounced (from $17.7 \%$ for women trained in economics and business to $26.6 \%$ for those with a qualification in theology) than differences by occupation and educational field combined (from $11.4 \%$ for women who worked as customs, tax and related government-associated professionals to $28.9 \%$ for those employed as lawyers and consultants). 
Table 3:

Childlessness, educational field and occupation; Greek women with a university degree born in 1955-1959

\begin{tabular}{|c|c|c|}
\hline & All & $\begin{array}{l}\text { Percentage } \\
\text { childless }\end{array}$ \\
\hline \multicolumn{3}{|l|}{ Educational fields } \\
\hline Humanities & 8867 & $19.1 \%$ \\
\hline Natural sciences & 3444 & $17.7 \%$ \\
\hline Theology & 350 & $26.6 \%$ \\
\hline Social sciences & 1751 & $22.7 \%$ \\
\hline Economics and business & 7415 & $17.6 \%$ \\
\hline Law & 4680 & $23.3 \%$ \\
\hline \multicolumn{3}{|l|}{ Occupations } \\
\hline Secondary education humanities teachers (public) & 5064 & $16.8 \%$ \\
\hline Secondary education natural sciences teachers (public) & 1817 & $13.7 \%$ \\
\hline Secondary education theology teachers (public) & 255 & $23.1 \%$ \\
\hline Secondary education social sciences teachers (public) & 114 & $18.4 \%$ \\
\hline Secondary education economics and business teachers (public) & 264 & $16.7 \%$ \\
\hline Total (Secondary education teachers - public) & 7514 & $16.3 \%$ \\
\hline Secondary education humanities teachers (private) & 960 & $21.9 \%$ \\
\hline Secondary education natural sciences teachers (private) & 151 & $17.2 \%$ \\
\hline Secondary education theology teachers (private)* & 2 & $50.0 \%$ \\
\hline Secondary education social sciences teachers (private)* & 30 & $23.3 \%$ \\
\hline Secondary education economics and business teachers(private) & 63 & $22.2 \%$ \\
\hline Total (Secondary education teachers - private) & 1206 & $21.4 \%$ \\
\hline Lawyers and consultants & 1636 & $28.9 \%$ \\
\hline Public notaries & 380 & $16.3 \%$ \\
\hline Public prosecutors and judges & 481 & $24.7 \%$ \\
\hline Total legal professionals & 2497 & $26.2 \%$ \\
\hline Economists - Freelance occupation & 315 & $26.3 \%$ \\
\hline Economists - Administrators in the public sector & 542 & $17.5 \%$ \\
\hline \multicolumn{3}{|c|}{ Economists - Customs, tax and related government associated professionals } \\
\hline & 446 & $11.4 \%$ \\
\hline Total (Economists) & 1303 & $17.6 \%$ \\
\hline \multicolumn{3}{|l|}{ Occupational categories not included in the above } \\
\hline Law - Not legal professionals & 2183 & $20.1 \%$ \\
\hline Humanities - Not secondary education teachers & 2843 & $22.4 \%$ \\
\hline Natural sciences - Not secondary education teachers & 1476 & $22.8 \%$ \\
\hline Theology - Not secondary education teachers & 93 & $35.5 \%$ \\
\hline Social sciences - Not secondary education teachers & 1607 & $23.0 \%$ \\
\hline $\begin{array}{l}\text { Economics and business - Not secondary education teachers or } \\
\text { economists in the above occupations }\end{array}$ & 5911 & $17.3 \%$ \\
\hline
\end{tabular}

*Small odd group, only used for summarising the number of women in the corresponding category

Overall, we find that the diversity of fertility among women is not only empirically associated with the pattern of childlessness by field of education, but that institutional aspects of the labour market, mainly employment security, employment content and income prospects, together with women's level of education and field, play an important role in their ultimate fertility. 


\section{Discussion and conclusion}

In this study we have used data derived from the 2001 Greek census to examine, in the first instance, the empirical relationship between educational field, educational level and fertility. In the second stage we have investigated the extent to which a woman's profession tends to modify the impact of educational field on fertility as well as the pattern of fertility by educational field.

Our results confirm the assumption, already raised by other studies, that higher education does not systematically result in higher childlessness. In several cases, educational field is as important as educational level. We found that the Greek pattern of childlessness by educational field has a lot in common with that found in other countries, with women educated in teaching and health care having lower levels of childlessness than most others on any educational level. Among the several factors related to an educational system, which may influence the relationship between education and childlessness, we emphasised the association between education and the labour market and, mainly, the distinction between employment opportunities in the public and the private sector. Our results indicate that women's professions tend to modify the pattern of childlessness by educational field. Women's occupations are associated very often with a lower rate of childlessness in comparison to the rate obtained if only the association between educational field and fertility had been considered.

Overall, we find that the pattern of childlessness by educational field alone does not explain the diversity of fertility among women. Educational field along with occupational characteristics play an important role in shaping women's reproductive behaviour. It is obvious that we need to identify better the underlying features associated with occupational characteristics and educational field and level that influence fertility behaviour. Even if it is very likely that differences in women's preferences towards family and work might be reflected in their educational choices, there is no doubt that the institutional aspects of education and, in particular, its structure and organisation, play an important role in shaping fertility outcomes. Nevertheless, we must not underestimate the institutional aspects of the labour market and, more specifically, those which make family and working life more compatible. Undoubtedly, these aspects must be further analysed in order to underline the different working conditions for women with the same or different education.

\section{Acknowledgments}

The author acknowledges Jan Hoem, Gerda Neyer and Gunnar Andersson for their encouragement in realising this study, Jan Van Bavel for providing unpublished work and the National Statistical Service of Greece for providing the data. Helpful comments from reviewers, editors, participants at the conference 
Education and Demography, organised by the Vienna Institute of Demography, 30 November to 1 December, 2009, Cleon Tsimbos, Georgia Verropoulou and Kate Michalopoulou are gratefully acknowledged.

\section{References}

Alipranti-Maratou L., C. Bagavos, M. Papadakis, and V. Papliakou. 2002. Population and Education in Greece: Trends and Prospects. Athens, National Centre for Social Research Editions (in Greek).

Bagavos, C. 2004. "The Situation of Families in Greece: General Monitoring Report.” In: B. Cizek and R. Richter (eds.) Families in EU-15. Policies, challenges and opportunities. Vienna, Austrian Institute for Family Studies-European Observatory on the Social Situation, Demography and Family, pp.127-139.

Becker, G. S. 1981. A Treatise on the family. Cambridge, Massachusetts, Harvard University Press.

Cigno, A. 1991. Economics of the family. Oxford, Clarendon Press.

European Commission. 2009. Key Data on Education in Europe 2009. Luxembourg, Office for Official Publications of the European Communities.

European Commission. 2003. Structures of Education, Vocational Training and Adult Education Systems in Europe-Greece. Eurydice Network on Education Systems and Policies in Europe, «http://www.eurydice.org».

Hoem, J., G. Neyer, and G. Andersson. 2006a. "Education and childlessness: The relationship between educational field, educational level, and childlessness among Swedish women born in 1955-59." Demographic Research 14(15): 331-380.

Hoem, J., G. Neyer, and G. Andersson. 2006b. "Educational attainment and ultimate fertility among Swedish women born in 1955-59." Demographic Research 14(16): 381-404.

Kalmijn, M. 1996. "Effecten van opleidingsniveau, duur en richting op het tijdstip waarop paren hun eerste kind krijgen [Effects of educational level, school enrolment and type of schooling on the timing of the first birth]." Bevolking en Gezin 1996: 41-71.

KEPE (Centre for Planning and Economic Research). 2005. "Directive on the opening of the sector of services in the common European market: Economic and social implications for Greece." (in Greek). Report, Athens: KEPE. «http://www.kepe.gr/pdf/doc_int_market_gr.pdf».

Kneale, D. and H. Joshi. 2008. "Postponement and childlessness: Evidence from two British cohorts.” Demographic Research 19(58): 1935-1968.

Kreyenfeld, M. and D. Konietzka. 2008. "Education and Fertility in Germany." In: I. Hamm, H. Seitz and M. Werding (eds.) Demographic Change in Germany. The Economic and Fiscal Consequences. Berlin, Springer, pp.165-187.

Lappegård, T. 2002. "Educational Attainment and Fertility Patterns Among Norwegian Mothers." Documents, 2002/18. Oslo: Statistics Norway.

Lappegård, T. and M. Rønsen. 2005. "The multifaceted impact of education on entry into motherhood." European Journal of Population 21: 31-49.

Lesthaeghe, R. 1995. "The second demographic transition in Western countries: an interpretation.” In: K. O. Mason, and A.-M. Jensen (eds.), Gender and family change in industrialized countries. Oxford, Clarendon Press, pp.17-62. 
Neyer, G. and J. Hoem. 2008. "Education and Permanent Childlessness: Austria vs. Sweden. A Research Note." In: J. Surkyn, P. Deboosere, and J. van Bavel (eds.) Demographic Challenges for the 21st Century. A State of the Art in Demography. Bruxelles, VUB/Academia Press, pp.91-112.

Martín-García, T. 2009. "The effect of education on women's propensity to be childless in Spain: Does the field of education matter"? Working Paper No. 114, Moncalieri, Collegio Carlo Alberto.«www.carloalberto.org/working_papers».

Martín-García, T. and P. Baizán. 2006. "The impact of the type of educational enrolment on first births." European Sociological Review 22 (3): 259-279.

Oppenheimer, V. K. 1988. "A Theory of Marriage Timing." American Journal of Sociology 94: 563-591.

Oppenheimer, V. K. 1994. "Women's rising employment and the future of the family in industrial societies." Population and Development Review 20 (2): 293-342.

Rendall, M., E. Aracil, C. Bagavos, C. Couet, A. DeRose, P. DiGiulio, T. Lappegård, I. Robert-Bobée, M. Rønsen, S. Smallwood, and G. Verropoulou. 2009. "Increasingly Heterogeneous Ages at First Birth by Education in 'Conservative' Southern-European and 'Liberal' Anglo-American Family-Policy Regimes." Working Paper 676, Santa Monica, RAND. «www.rand.org/pubs/working_papers/WR676».

Schultz, T. P. 1976. "Determinants of fertility: a micro-economic model of choice." In: A. J. Coale (ed.) Economic Factors in Population Growth. London, MacMillan, pp. 89124.

Surkyn, J. and R. Lesthaeghe 2004. "Value orientation and the second demographic transition (SDT) in Northern, Western and Southern Europe: An update." In: G. Andersson and G. Neyer (eds.) Contemporary research on European fertility: Perspectives and developments. Edited Special Collection 3 of Demographic Research, pp.43-86.

Van Bavel, J. 2010. "Choice of study discipline and the postponement of motherhood in Europe: the impact of expected earnings, gender composition and family attitudes". Demography 47(2): 439-458.

Van de Kaa, D. J. 1987. "Europe's second demographic transition." Population Bulletin 42: 1-57.

Van de Kaa, D. J. 1996. "Anchored narratives: The story and findings of half a century of research into the determinants of fertility." Population Studies 50: 389-432. 